\title{
Immediate antiviral therapy for HIV-infected persons faces with various obstacles
}

\author{
Qi Tang ${ }^{1,2}$, Hongzhou $\mathrm{Lu}^{1,2,3, *}$ \\ ${ }^{1}$ Scientific Research Center, Shanghai Public Health Clinical Center, Fudan University, Shanghai, China; \\ ${ }^{2}$ Department of Infectious Diseases, Shanghai Public Health Clinical Center, Fudan University, Shanghai, China; \\ ${ }^{3}$ Department of Infectious Disease, Huashan Hospital Affiliated to Fudan University, Shanghai, China.
}

\begin{abstract}
Summary Human immunodeficiency virus (HIV)/acquired immune deficiency syndrome (AIDS) ranks eighth in the global burden of disease, making seriously threatens to global health. Given there is not yet a cure for HIV infection, antiretroviral therapy (ART) holds a key role not only in improving the prognosis of the patients, but also reducing the risk of HIV transmission. The immediate initiation of ART has been recommended in domestic and foreign policies and guidelines, yet the implementation of this strategy is not satisfactory. In developing countries and even in some developed countries, it still takes a long time for patients to go from the diagnosis of HIV infection to the acceptance of ART. Clarifying the obstacles to the implementation of immediate ART and finding strategies to cope with them have emerged as key problems in response to HIV/AIDS.
\end{abstract}

Keywords: HIV/AIDS, antiviral therapy, health service quality

Human immunodeficiency virus (HIV)/acquired immune deficiency syndrome (AIDS) ranks eighth in the global burden of disease in 2017, making seriously threatens to global health $(1-5)$. Due to its complexity and lethality, there are total 36.9 million people living with HIV and 1.8 million people newly infected with HIV in 2016 globally, and total 849,602 people with HIV/AIDS and 262,442 people AIDS-related deaths as of September 30, 2018 in China (6,7). Curbing the AIDS epidemic is an important part of the United Nations 2030 sustainable development goals $(8,9)$, which still has considerable challenges.

Given there is not yet a cure for HIV infection, antiretroviral therapy (ART) holds a key role not only in improving the prognosis of the patients, but also reducing the risk of HIV transmission (10-17). The guidelines of World Health Organization (WHO), European AIDS Clinical Society (EACS), U.S.

Released online in J-STAGE as advance publication June 18, 2019.

*Address correspondence to:

Dr. Hongzhou Lu, Shanghai Public Health Clinical Center, Fudan University, No.2901, Caolang Road, Jinshan District, Shanghai 201508, China.

E-mail: luhongzhou@fudan.edu.cn
Department of Health and Human Services (DHHS) and Chinese Medical Association (CMA) all recommended that ART should be initiated in all HIV-infected adults, regardless of $\mathrm{CD}^{+}$cell count (18-20).

However, the implementation of this strategy is not satisfactory. In developing countries and even in some developed countries, it still takes a long time for patients to go from the diagnosis of HIV infection to the acceptance of ART. The European Centre for Disease Prevention and Control (ECDC) report showed that only 16 of the 23 countries in Europe and Central Asia was reported to start treatment within one month of diagnosis (21); Oliver Bacon's study showed median time from diagnosis to first virologic suppression in San Francisco was 134 days in 2013 (22); Zunyou Wu's study showed the time from HIV confirmation to ART initiation was 53 days without intervention (23).

Clarifying the obstacles to the implementation of immediate ART has emerged as key problems in response to HIV/AIDS. The key obstacles in current research can be summarized in the following three aspects. $i$ ) Demand-side. Risk factors for delayed ART initiation include the key populations of men having sex with men (MSM), injecting drug users, male, older age, unmarried or divorced, etc., and the HIV-infection persons with long-term out-migrating/working, 
refusal of treatment, negative psychological emotions, treatment related costs, etc. (24-26). ii) Supply-side. Health system challenges are a barrier to getting people diagnosed with HIV onto treatment in many countries, including the insufficient knowledge and skills of health professionals, inadequate referral mechanism, weak confidentiality and availability of treatment options, etc. $(27,28)$. iii) Intervention-side. This section includes the social and cultural issues, including the laws and policies, stigma and discrimination, tedious treatment process, etc. $(21,26,29)$.

Nevertheless, due to the short emergence time of this phenomenon, few studies to provide systematic, quantitative and suitable countermeasures and suggestions for this issue. Finding the systematic and quantitative strategies to cope with these obstacles has important theoretical value and practical significance. Firstly, conduct more multi-center clinical trials to further promote the updating of guidelines. In 2017, WHO guidelines put forward the strategy of Rapid ART Initiation (30), suggesting that all HIV-infected persons must start ART rapidly (less than 7 days after HIV positive diagnosis); and for those ready to begin the treatment, ART should be initiated on the same day. But it also noted that medical resources are key constraints, so more clinical trials are needed. Secondly, except for identifying the key obstacles, revealing the underlying mechanisms of such obstacles and selecting the optimal coping strategies based on mechanism research also important for optimizing HIV prevention and control policies.

\section{References}

1. GBD 2017 Causes of Death Collaborators. Global, regional, and national age-sex-specific mortality for 282 causes of death in 195 countries and territories, 19802017: A systematic analysis for the Global Burden of Disease Study 2017. Lancet. 2018; 392:1736-1788.

2. Brinsdon A, Abel G, Desrosiers J. "I'm taking control": How people living with HIV/AIDS manage stigma in health interactions. AIDS Care. 2017; 29:185-188.

3. Stuardo Ávila V, Manriquez Urbina JM, Fajreldin Chuaqui V, Belmar Prieto J, Valenzuela Santibáñez V. Model of socio-cultural dimensions involved in adherence to antiretroviral therapy for HIV/AIDS in public health care centers in Chile. AIDS Care. 2016; 28:1441-1447.

4. Walsh FJ, Bärnighausen T, Delva W, Fleming Y, Khumalo G, Lejeune CL, Mazibuko S, Mlambo CK, Reis R, Spiegelman D, Zwane M, Okello V. Impact of early initiation versus national standard of care of antiretroviral therapy in Swaziland's public sector health system: Study protocol for a stepped-wedge randomized trial. Trials. 2017; 18:383.

5. Lake S, Kerr T. The challenges of projecting the public health impacts of marijuana legalization in Canada. Comment on "Legalizing and regulating marijuana in Canada: Review of potential economic, social, and health impacts". Int J Health Policy Manag. 2016; 6:285-287.

6. The Joint United Nations Programme on HIV/AIDS.
UNAIDS DATA 2018. http://www.unaids.org/sites/ default/files/media_asset/unaids-data-2018_en.pdf (accessed April 2, 2019)

7. Chinese Center for Disease Control and Prevention. The national epidemic of AIDS and STDs in the third quarter of 2018. Zhongguo Ai Zi Bing Xing Bing. 2018; 24:1075. (in Chinese)

8. United Nations. Global Issues AIDS. http://www.un.org/ en/sections/issues-depth/aids/index.html (accessed April 22, 2019)

9. United Nations. Sustainable Development Goals. Goal 3: Ensure healthy lives and promote well-being for all at all ages. https://www.un.org/sustainabledevelopment/health/ (accessed April 13, 2019)

10. Granich RM, Gilks CF, Dye C, De Cock KM, Williams BG. Universal voluntary HIV testing with immediate antiretroviral therapy as a strategy for elimination of HIV transmission: A mathematical model. Lancet. 2009; 373:48-57.

11. Lodi S, Phillips A, Logan R, et al. Comparative effectiveness of immediate antiretroviral therapy versus CD4-based initiation in HIV-positive individuals in highincome countries: Observational cohort study. Lancet HIV. 2015; 2:e335-343.

12. Kroon EDMB, Phanuphak N, Shattock AJ, Fletcher JLK, Pinyakorn S, Chomchey N, Akapirat S, de Souza MS, Robb ML, Kim JH, van Griensven F, Ananworanich J, Wilson DP. Acute HIV infection detection and immediate treatment estimated to reduce transmission by $89 \%$ among men who have sex with men in Bangkok. J Int AIDS Soc. 2017; 20:21708.

13. Molina JM, Grund B, Gordin F, et al. Which HIV-infected adults with high CD4 T-cell counts benefit most from immediate initiation of antiretroviral therapy? A post-hoc subgroup analysis of the START trial. Lancet HIV. 2018; 5:e172-e180.

14. Kuznik A, Iliyasu G, Habib AG, Musa BM, Kambugu A, Lamorde M. Initiation of antiretroviral therapy based on the 2015 WHO guidelines. AIDS. 2016; 30:2865-2873.

15. Zhao Y, Wu Z, McGoogan JM, Shi CX, Li A, Dou Z, Ma Y, Qin Q, Brookmeyer R, Detels R, Montaner JSG. Immediate antiretroviral therapy decreases mortality among patients with high CD4 counts in China: A nationwide, retrospective cohort study. Clin Infect Dis. 2018; 66:727-734.

16. Ming Z, Prybylski D, Cheng F, Airawanwat R, Zhu Q, Liu W, Huang S. Two-year prospective cohort study on quality of life outcomes among people living with HIV after initiation of antiretroviral therapy in Guangxi, China. J Assoc Nurses AIDS Care. 2014; 25:603-613.

17. Ding Y, Duan S, Wu Z, Ye R, Yang Y, Yao S, Wang J, Xiang L, Jiang Y, Lu L, Jia M, Detels R, He N. Timing of antiretroviral therapy initiation after diagnosis of recent human immunodeficiency virus infection and CD4(+) T-cell recovery. Clin Microbiol Infect. 2016; 22:290.e5-8.

18. European AIDS Clinical Society. EACS Guidelines Version 8.0. 2015. http://www.eacsociety.org/files/ guidelines_8_0-english_web.pdf(accessed April 14, 2019)

19. Günthard $\overline{H F}$, Saag MS, Benson CA, del Rio C, Eron JJ, Gallant JE, Hoy JF, Mugavero MJ, Sax PE, Thompson MA, Gandhi RT, Landovitz RJ, Smith DM, Jacobsen DM, Volberding PA. Antiretroviral drugs for treatment and prevention of HIV infection in adults: 2016 recommendations of the international antiviral societyUSA panel. JAMA. 2016; 316:191-210. 
20. Chinese Medical Association, Chinese Center for Disease Control and Prevention. Guidelines for AIDS Diagnosis and Treatment in China (2018 edition). Zhonghua Nei Ke Za Zhi. 2018; 57:867-884. (in Chinese)

21. European Centre for Disease Prevention and Control. HIV treatment and care. Monitoring implementation of the Dublin declaration on partnership to fight HIV/AIDS in Europe and central Asia: 2017 progress report. https:// ecdc.europa.eu/sites/portal/files/documents/HIV\%20 treatment $\% 20$ and $\% 20$ care.pdf (accessed April 15, 2019)

22. Bacon O, Chin JC, Hsu L, Cohen SE, Sachdev D, Jones D, Fuchs J, Scheer S, Buchbinder SP, Havlir DV. The rapid ART program initiative for HIV diagnosis (RAPID) in San Francisco. 25th Conference on Retroviruses and Opportunistic Infections (CROI). March 4-7, 2018. Boston. Abstract 93. http://www.croiconference.org/ sessions/rapid-art-program-initiative-hiv-diagnosesrapid-san-francisco (accessed April 24, 2019)

23. Wu Z, Zhao Y, Ge X, et al. Simplified HIV testing and treatment in China: Analysis of mortality rates before and after a structural intervention. PLoS Med. 2015; 12:e1001874.

24. Sun J, Liu L, Shen J, Chen P, Lu H. Trends in baseline CD4 cell counts and risk factors for late antiretroviral therapy initiation among HIV-positive patients in Shanghai, a retrospective cross-sectional study. BMC Infect Dis. 2017; 17:285.

25. Gu D, Mao Y, Tang Z, et al. Loss to follow-up from HIV screening to ART initiation in rural China. PLoS One.
2016; 11:e0164346.

26. Milloy MJ, Montaner J, Wood E. Barriers to HIV treatment among people who use injection drugs: Implications for 'treatment as prevention'. Curr Opin HIV AIDS. 2012; 7:332-338.

27. Loughlin A, Metsch L, Gardner L, Anderson-Mahoney P, Barrigan M, Strathdee S. Provider barriers to prescribing HAART to medically-eligible HIV-infected drug users. AIDS Care. 2004; 16:485-500.

28. Viciana-Fernández P, Falcó V, Castaño M, de los SantosGil I, Olalla-Sierra J, Hernando A, Deig E, Clotet B, Knobel H, Podzamczer D, Pedrol PD, Grupo de trabajo Bridgap. Barriers to ART initiation in HIV infected subjects and with treatment indication in Spain. Why don't they start their treatment? Bridgap Study. Enferm Infecc Microbiol Clin. 2015; 33:397-403.

29. Alfonso V, Bermbach N, Geller J, Montaner JS. Individual variability in barriers affecting people's decision to take HAART: A qualitative study identifying barriers to being on HAART. AIDS Patient Care STDS. 2006; 20:848-857.

30. World Health Organization. Guidelines for managing advanced HIV disease and rapid initiation of antiretroviral therapy. 2017. https://apps.who.int/iris/bitstream/hand le/10665/255884/9789241550062-eng.pdf;jsessionid $=6$ 3212 FD 3FA665A52E01C69084621944A ? sequence $=1$ (accessed April 3, 2019)

(Received May 2, 2019; Revised June 11, 2019; Accepted June 12, 2019) 